\title{
THE EDUCATION OF ROMA IN GREECE
}

\author{
Dimitris K. Vergidis \\ University of Patras, Department of Education,
}

Rion-Patras, 26500, Greece

\begin{abstract}
In this paper we examine schooling as a factor in the social integration of the Roma who are Greek citizens. It refers to the living conditions of the Greek Roma and the transformation which their social organization is undergoing, taking their economic activities as a starting point. In order to tackle the educational exclusion of the Roma, two different educational policies have taken shape. There is the official educational policy which argues that the educational exclusion of the Roma should be dealt with through positive discrimination so that the romani children can be integrated into regular schools. On the other hand, out of criticism of the role of the school in the reproduction of social inequalities, springs the demand for a different educational policy which would adapt schooling to the culture of the Roma and respond to their particular needs.
\end{abstract}

\section{Indexing terms/Keywords}

Roma, Roma pupils, human rights, schooling of Roma, greek school minorities

\section{Academic Discipline And Sub-Disciplines}

Science Education

\section{Council for Innovative Research}

Peer Review Research Publishing System

Journal of Social Science Research

\author{
Vol.1 No.3 \\ editor@ijssronline.com \\ www.cirworld.com, www.ijssronline.com
}




\section{INTRODUCTION}

The predominance of neo-liberalism, as an ideology and as economic policy, and the ensuing shrinking of the welfare state, resulted in the worsening of socio-economic inequalities and social exclusion. These socio-economic phenomena constituted the ground upon which xenophobia and neo-racism developed.

According to Balibar, neo-racism is different from racism: it is racism where the main issue isn't the biological heredity but the irreducible cultural differences (1991: 35). The different cultural traditions of minority groups create obstacles or are presented as obstacles (by the schools, by the norms of international communication) to the acquisition of culture, and assimilation is presented as progress, emancipation, the granting of rights (op.cit.: 42-43).

We should point out that the concept of minority does not necessarily originate in a numerical reality, it concentrates social relationships of power (Wallerstein I., 1991a: 126). It is obvious, for example, that the staff of the European Commission who are citizens of the various member-states and the employees in their Permanent Delegations do not constitute minorities in Brussels.

Social exclusion is a structural element of contemporary post-industrial societies, given that under conditions of globalization and the intensification of international economic competition, the securing of high profits and in some cases the survival of problematic businesses, depends on cheap work force (Wallerstein I., 1991b: 163-4):

a. A labour force flexible over time, available for seasonal work and for periods of increased production, the cost of which is limited to expenditure which is directly related to production (without compensation, health insurance rights, etc).

b. A work force flexible in space, which moves without the payment of transportation and reestablishment costs and without the ensuring of dignified and acceptable living conditions.

c. Minimization of the cost of labour, through the bypassing of labour and insurance legislation and the infringement of the economic and social gains and rights of the workers.

The minorities, the immigrants - and a fortiori illegal immigrants - are, on the one hand, victims of overexploitation, and on the other, victims of neo-racism, which marginalizes them and forces them to take on the worst and most badly paid jobs, with the worst possible working conditions.

These developments contribute to the growth of a secondary cheap labour market, which is connected to the underground economy and the bypassing of labour legislation, and often strengthen the social exclusion which mainly afflicts the minorities and disadvantaged population groups.

Educational exclusion, being deprived of the right to education, is a dimension of social exclusion. Next we will refer to the Roma who are Greek citizens and their relationship with the school in Greece.

\section{GREEK ROMA}

There are estimated to be about 150,000 Greek Roma (Exarhos G., 2004: 200). Liegeois and Gheorghe calculate them to be between 160,000 and 200,000 (1995) and according to the National Commission for Human Rights (N.C.H.R), about 250,000 individuals of Roma descent live in Greece (National Commission for Human Rights, 2001: 1). The Integrated Development Programme for the Social Integration of Greek Roma estimates their number to be $250-300$ thousand individuals (Markou G., 2008). The majority of them are illiterate and use the traditional network of communication and learning, which is based mainly on imitation, on participation and on non verbal communication. It is calculated that $60 \%$ of Roma are completely illiterate (National Commission for Human Rights, 2004: 9). As is characteristically pointed out: "There is no tradition of reading and writing in the Roma community, since the Roma language is oral, the Roma make use of the members of the family or the community who can read and write at least rudimentarily, and don't feel their lack of knowledge of reading and writing so intensely." (Vasileiadou M., Pavli-Korre M., 1996: 26).

For centuries they managed to preserve their language and their particular cultural characteristics, living nomadically or on the outskirts of urban centres, and carrying out various economic activities, adapted each time to local circumstances, always within the framework of their own social organization. A basic parameter which determined their economic activities was the continuous wandering, traveling.

Within the context of the rapid socio-economic developments, after the Second World War and the Civil War (abandonment of outdoor life, urbanism, economic growth etc.), Greek Roma were compelled to gradually adapt their traditional economic and livelihood activities, as well as their way of life. According to a relevant study "Nowadays more and more Roma are seeking permanent settlement. Despite this, the majority of them are denied housing and live, even in the winter, in tents or in squalid huts." (General Secretary for Adult Education, n.d.:17). We should add that, as has emerged from other research "...most Roma wish for a normal, privately owned house like everybody else....already $50 \%$ of them have lived in the same place for over 20 years (N.C.H.R., 2001: 4).

However, the permanent settling of a significant part of the Roma population in urban centres or on the outskirts of urban or semi-urban settlements and their gradual integration into the market economy posed in a marked - and often confrontational - manner, the question of their social integration, on an individual and collective level. 
It seems that permanent settlement really does constitute a development of decisive significance for the Roma, and on the one hand it is the result of wider changes, not only for the Roma themselves but in the surrounding society, and on the other hand, speeds up these changes. As is pointed out: "The basic ...structures of Roma society are disturbed during the process of their permanent settlement and urbanization. The home becomes a factor of decisive significance." (Terzopoulou M., Georgiou G., 1996: 19).

The settled Roma gradually adopt the way of life of the cities and with the passing of time the extended family loses its functionality as a context for the socialization of the new generation. "For those who choose to settle in urban districts, social organization is lost, family lines break up and cease to constitute a point of reference, losing their potential for the socialization and control of the individuals." (op.cit.).

Other Roma groups face ghettoisation and social exclusion. "Those who, seeking to preserve the cohesion of the group, and choose to settle in blighted areas on the outskirts of urban centres, and camp sites, quickly become ghettoized and are reduced to conditions of the toughest social exclusion." (op.cit.)

These developments have created new needs for the Roma, and new relationships with their social environment. The dramatic situation in which they found themselves has been described by some writers in the most vivid way

"For all those people there is a common denominator: For them there is no 'God', justice, humanity, sympathy!

For all those people there is a common denominator: For them there is no right to even basic living conditions, no right to education and schooling, no right to work, no right to cultural goods, no right to life ..." (Exarhos G., 2004: 195).

Their social and technical knowledges, which helped them survive for centuries preserving their independence and autonomy, their nomadic way of life and their cultural singularity lost a large part of their functionality under the new conditions. We should note that a basic cultural characteristic of the Roma is their developed traditional network of communication and learning, which ensured the reproduction of their socio-economic practices and their particular characteristics. As Fraser mentions, the family values comprise the basic foundation of the life of Roma, something which becomes obvious from the way they earn their livelihood. The children usually start to contribute as soon as they grow up a little. Although not usually very educated in the conventional sense, the Roma children, by following the grown ups, watching and helping them at work and listening to their advice, learn different jobs and skills. (1998: 310).

The Roma appear traditionally to use the same survival know-how as the cities' poor, in other words at structural level, the extended family and the wider network of useful social relationships, and at the level of survival strategies, professional mobility, multiprofesionalism and small-time tradesmanship. According to Pizanias, survival know-how is composed of the general cultural vested interests which, historically, have made up knowledge. They have acquired in other words fixed characteristics, which are expressed only practically, directly, experientially and are not expressed in organized and direct speech (1993: 120).

Just as the cities' poor were a population - "quick sand" (op. cit: 150), "ready to move in whatever direction, on whatever terms, available for whatever work" (op. cit: 140), in a similar way: The Roma community seems to adapt its professions, its economic structure more generally, so that, when it has to, the binary system can be activated, the alternation between permanent establishment and change of place, movement. (Karathanasi E., 2000: 92).

Terzopoulou and Georgiou offer another interpretation of the value system and way of life of the Roma, claiming that:

"... many of their impressive characteristics today (collectiveness, orality of their tradition, nomadic life, extended family, nuptial strategies based on paternal family relationships, noisy celebrations, traditional dress, etc), which make them stand out in contemporary states, were until recently common grounds for traditional communities, which were simply abandoned and forgotten." (1996: 27). Vaxevanoglou supports the same view (2001: 67).

Greek Roma preserved, and continue to preserve to a significant degree, survival know-how as it was shaped historically, until the last decades of the $20^{\text {th }}$ century. However now that their transactions with non Roma are becoming more frequent in the context of the market economy, as well as their transactions with the state bureaucracy, the traditional network of communication and learning is losing the effectiveness which it had been ensured within the closed and relatively self-sufficient Roma group. The written network of communication and learning no longer represents a foreign reality unrelated to the Roma. Their socio-economic development obliged them to move beyond - or at least start to move beyond - the bounds of their closed social organization and to adapt their survival know-how to the new conditions.

The process of the transformation of the Roma' closed social organization is characterized then by contradictions, oppositions and conflicts with the dominant society. The transfer of their traditional outdoor way of life to urban and semiurban settlements, their difficulty in responding to the rules of faceless social and economic machinery, neo-racism and generally their social exclusion, intensify the problem of their contemporary social integration and create intense confrontational situations. We should add that conflict is not only observed between Roma and the dominant society. According to Liegeois, ... due to multiple pressures, more and more Roma and Travelers are making use of more and more limited economic sources. This brings about economic competition, which upsets the relationships, the solidarity and may create conflicts among the Roma, when others come from elsewhere to share the same space. The differentiations between family groups which are prosperous, and others which are poor now become more evident than before. (1999: 105).

Greek Roma appear to be gradually assimilating into the market economy. In particular: 
a. They comprise a readily available, cheap work force mainly for agricultural production. They work within the context of the black market, on low wages, without insurance etc. The Roma gather large quantities of agricultural produce and the local economy's need for their participation is huge (Karathanasi E., 2000: 198). They constitute a work force that is flexible regarding time and space, and at low cost, factors crucial for the harvesting of agricultural produce at the appropriate time. However, in recent years they face competition from economic immigrants, who are forced to work for even lower pay (N.C.H.R., 2004: 10).

b. They create networks for the sale of cheap - and possibly inferior quality - industrial and agricultural products. As Vaxevanoglou points out, "The range of products is very wide and the only fixed criteria is that they be very cheap. It goes without saying that cheap becomes shoddy, or simply faulty." (2001: 118). Gradually, the Roma' economic activities are to be characterized more and more by competition and the conflicts of the market economy. We mention characteristically that in recent years the Roma deal in copies of expensive goods, otherwise known as fake goods, which are either imported ready, or else their distinguishing marks are tampered with (Vaxevanoglou A., 201: 118-9).

In summarizing, we could say that the development of the Roma' economic activities is interpreted using the theory of the double labour market, according to which the labour market is separated into primary and secondary. The primary market is characterized by regular employment, high wages and better working conditions, while the secondary comprises inferior occupations with lower wages or income, often of borderline legality, without potential for advancement, as well as illegal activities. The secondary labour market includes the most undesirable and dangerous jobs.

A necessary prerequisite for freeing the Roma from the secondary labour market, is clearly at least a basic knowledge and use of the written network of communication and learning, and in general their integration into the education system. Consequently, it is not by chance that the number of Romani children in school is rising, a fact which requires, fixes and finally signals significant differentiations in the social and economic organization of the Greek Roma: permanent settlement, a relative limiting of child labour, a limiting of family moves for seasonal work, as well as the creation of enclaves of economic activity (Vergidis D., 1995: 59). The enclaves of economic activity especially place the Roma at the level of well-off employers and employees.

We note that according to Liegeois, in the second half of the $20^{\text {th }}$ century assimilative policies, accompanied by humanistic reasoning, changed the means of approaching and dealing with Roma and Travellers. A tendency towards a shift from suppression to prevention and strengthening of social control, so as to avoid conflicts and reduce the chances of deviating from the rule, was created. (1999: 241).

\section{EDUCATION POLICIES AND ROMA}

The education of Roma as a right should be examined on two levels. On the one hand, as a statutory human right, in other words, as an application of compulsory education for all children, including Romani children, and on the other hand, as a struggle on the part of the Roma themselves to have the right to an education that responds to their needs and their social characteristics.

The basic characteristic of greek educational policy is uniformity at school, despite all the attempts that have been made in recent years with the establishment of programmes of environmental studies, or health education.

As we had already mentioned in the 90s, (Vergidis D., 1995), policies of educational exclusion of Romani children, which is a dimension of their social exclusion, falls into two categories. According to this categorization, which was adopted by the National Commission for Human Rights (N.C.H.R.) (2001: 6-7), the Greek Group for the Rights of Minorities (G.M.R.G.) (2002: 12-13), the educational integration of the Roma is obstructed by:

a. The active exclusion of Romani children, either through the vigorous mobilization of the local community - with violence, or more often with threats - or through milder administrative means.

b. The passive exclusion of Romani children in the school classroom, through the simple acceptance of their presence and their marginalization.

Evidence from the Ministry of Education shows that the dropout rate of Roma children from primary school fell from $75 \%$ in 1997 to 24\% in 2004 (N.C.H.R., 2004: 10). We don't know, however, to what extent this represents actual educational integration (Vergidis D., 1998) or the temporary results of actions which are based on the provision of financial support.

We should explain that the exclusion of Romani children from school is not exclusively an educational issue, but is related to the position of the Roma in the local communities and to dominant stereotypes.

As Exarhos points out (2004: 216-217):

- The primary issue for the Roma is the human right to housing. Without satisfactory housing, it will not be possible for the Roma to have access to social and political rights.

- A second significant issue for the Roma is the human right to employment.

- A third large issue is social welfare and insurance. It should be noted that $70 \%$ of Greek Roma are entirely uninsured (G.M.R.G., 2002: 12).

The human rights mentioned above are considered to be prerequisites for the right to education and learning. 
At this point we need to refer to the relationship of the Roma with the school. According to a relevant study "...their continual movement and the squalor of their living conditions place serious barriers in front of every attempt at steady integration of Roma children into the education system." (General Secretary for Adult Education, n.d.: 17). However this position does not explain the active and mainly the passive exclusion of the Roma from education, nor does it explain the unwillingness of the relatively well-off, settled Roma to effectively support the educational integration of their children.

As Vasileiadou and Pavli-Korre observe: "The school in its current form denies and rejects Roma children. It denies and rejects their appearance, their mother tongue, their culture, their skills and experiences. Roma often complain about a lack of respect for their culture in the official school system. The school as an institution is a basic arena of conflict between the Roma and non Roma community." (1996: 28). According to the same writers, the rejection of the Roma by the school is due to the stereotypes and prejudices of the non-Roma who express themselves with negative views and behaviours towards them (1996: 41). It is important we emphasize that the educational integration of the Roma is difficult, for which the school is responsible, even when it concerns permanently settled Roma families with a satisfactory income and good living conditions (Vergidis D., 1998). As Gotovos mentions, there are three basic reasons behind the negative attitude as far as school integration of Roma children is concerned: fear from the presence of Roma in the school, fear of a drop in the level of the school, the change in the daily routine of the teachers who face difficulties with the Roma children (2006).

What is odd is that together with the accusation of the educational exclusion of the Roma, it is claimed that: "Traditional school methods are not suitable for teaching the Roma child (Vasileiadou M., Pavli-Korre M., (1996: 28). The question is whether in fact "The Roma are educated with the traditional Roma ways and there is a great gap between the methods and the objectives of the two systems. The Roma child feels the conflict between the two worlds very intensely, the world of the family/community and the school, which represent two different value systems, of the Roma and non Roma community..." (op.cit). In this case, it appears that two parallel systems function, two different worlds in conflict with each other. In contrast to the dominant community, "The [Romani] children are socialized early...participating freely in the social life and travels the children are educated, they are taught the economic activities they will go in for as well as the codes of communication through the interfamily and other networks and from early on, take on the roles for which they are destined." (Terzopoulou M., Georgiou G., 1996: 18-19). This view rests on the acknowledgement that the socialization of the Roma reproduces economic activities, codes of communication and roles that remain to a large extent immutable and stable in time and space.

Next we will set forth in brief the main arguments which differentiate the school and the Roma culture (Vasileiadou M., Pavli-Korre M., 1996: 24, 25, 32).

- The rejection of the school by the Roma - either consciously or unconsciously - functions to strengthen the preservation of their own culture and their cultural identity and aids the social and psychological balance of the group.

- For the Roma, the school is a foreign institution, without a tradition in their social organization, and comprises an integral part of a world that was for centuries a threat to them.

- The Roma parent, in sending his child to school endangers the preservation of his culture, the school representing the threat of assimilation.

- In his first contact with the school, the Romani child encounters a new world, totally different from the one he is so far familiar with.

- When the child attends school, he loses valuable time from the gaining of knowledge and skills which the professional occupation of his Roma group requires.

- The Roma children's success at school involves dangers, for the Roma community, because it implies to a certain degree their distancing from their family and the weakening of community cohesion.

- The Roma recognize the usefulness of the school only for the rudimentary learning of reading, writing and arithmetic.

However, a precondition of this line of reasoning remains the acknowledgement of an immutable Roma culture which is threatened by the school. In addition, the Roma, using the technological products of the dominant society, are subject to invisible influences on their way of life. The television, the radio and the cinema, bring the outside world closer to them, affecting the younger generation in particular (Fraser A., 1995: 316).

As we ascertain, there are two different views of human rights which lead to two different educational policies. The first focuses on the implementation of compulsory education for all citizens and all children, without exclusions and discriminations, aimed at the full integration into the written network of communication and learning. The chief measure which has been taken for the implementation of this policy is the payment of an allowance to Roma families who send their children to school. The second focuses on acceptance and respect, or on the acceptance of the singularity of the Roma and their culture and seems to lead to a parallel education network - e.g. in the form of parallel classes and extracurricular literacy lessons - adapted to the Roma' traditional way of life and all that this implies (frequent changes of home, frequent moves for work reasons, etc.). We note that positive experiences of extracurricular educational integration of Romani children do exist (Vergidis D., 1996).

For the promotion of the education of Romani children, two large scale programmes were carried out by the University of loannina. The project "Education of Roma Children" (1997-1999) and the project "Integration of Roma children into the school" (2002-2004). It appears that the contradiction we drew attention to was not solved within the context of these 
programmes either. An attempt was made to combine the two educational policies, with the functioning of reception classes and "preparatory classes", where special teaching material was used, as well as music laboratories for the Romani children. The question is whether and to what extent these groups developed into parallel classes.

We should make clear that the integration of the Roma into the particular socio-historic reality necessarily entails their integration into its structural contradictions, competition and oppositions. It should be added that institutionalized competition and social mobility comprise component elements of the modern society. In addition, human rights "...as they have been incorporated into the constitutions of western countries, serve the legislative regulating of conflict." (Lenhart V., 206: 40). Consequently, the processing of education policy and strategies for the integration of Romani children into the school is defined:

- $\quad$ Either by the neo-liberal ideology and neo-liberal policy in education - and not exclusively in education - which is based on "rights - freedoms" of all citizens, Roma as much as non Roma (parental choice of school, competition between schools),

- Or by the powers that oppose neo-liberalism and demand "rights - provisions", effective actions for the democratization of education and the support of all those in education, as well as positive discrimination for all those in danger of educational exclusion, aimed at the moderating of competition and its consequences.

Within the context of this wider contradiction, the appeal to human rights is not enough for the processing of educational strategies for the integration of Roma. Instead it forms yet another ground for politico-social oppositions and conflicts.

\section{CONCLUSIONS}

Greek Roma are separated into strata. Some of them are settled in urban and semi-urban areas, in houses and with a relatively satisfactory income. Others live in dire conditions, mainly in depressed outlying areas, and move continually in the search for work.

The integration of Roma - or at least some of them - into the market economy and for some researchers, into the consumer society has created new needs and new relationships with the dominant society. Their traditional survival know-how is starting to become dysfunctional and incompatible with state machinery for the control of their economic activities. Hence, the majority of them are being pushed into the secondary labour market, taking on the most undesirable and dangerous forms of employment.

A vital prerequisite for freeing Roma from the secondary labour market is their educational integration and the collective exercising of their individual, political and social rights, with active state action and the ensuring of the necessary means (Lenhart V., 2006: 37).

The education of Roma as a right was examined on the one hand in its legislative form, in other words, in terms of the implementation of the required compulsory education, and on the other, as the demand for educational practices which respond to their needs and particular characteristics.

First of all, we should note that educational exclusion can be either active, with local bodies' refusal to register Romani children in school, or passive, with the marginalization of the Romani children in the classrooms. As we mentioned elsewhere, exclusion and neo-racism don't stop at the school door.

Next we referred to the material prerequisites for the educational integration of the Roma, which constitute human rights (housing, work, health care and insurance).

We ascertained that views on the educational integration of Roma focus on two problems. On the one hand, it is highlighted that the present school is looked on with some suspicion by the Roma - especially those hit by social exclusion - and is considered to be an institution of the dominant society, a threat to their culture and way of life. On the other hand the rejection of Romani children by the school and local community is denounced.

It is interesting to note that the social and educational integration of Roma is faced both positively, as a right, and negatively, as a threat to the Roma culture. However, the results and wider implications of the educational integration of the Roma and the already implemented education policies, as far as their reproduction and development and especially their social mobility are concerned, are not analysed.

\section{REFERENCES}

[1] Armstrong K.A. (2006), The 'Europeanisation of Social Exclusion: British Adaptation to EU Co-ordination. British Journal of Politics and International Relations, vol. 8, $79-100$.

[2] Balibar E. (1991), Does "neo-racism" exist? In Balibar E., Vallerstain I., Race, Nation, Class, differentiated identities, Athens, publ. O Politis.

[3] Democratic Dialogue (1995), Social Exclusion, Social Inclusion. Report No 2, November 1995. Belfast.

[4] Dousas D. (1997), Rom and racial discrimination in history, society, culture, education and human rights, Athens, Gutenberg, Social Science and Social Policy Library.

[5] Eberhard C. (1998), De l'universalite a une pluriversalite des Droits de l'Homme - Le paradigme "communautaire" comme "ecosysteme"? Droits de l'Homme et Dialogue Interculturel. 
[6] European Roma Rights Centre, Greek Helsinki Monitor (2003), Cleaning Operations. Excluding Roma in Greece, Country Report Series, No. 12, April.

[7] Exarhos G. (1996), These are the Roma, Athens, publ. Gabrilides.

[8] Exarhos G. (2004), Social Exclusion of the Roma, in Kasimati K., Social exclusion: the greek experience, Athens, Gutenberg, Library of Social Science and Social Policy, Centre of Social Morphology and Social Policy.

[9] Fraser A. (1995), The Roma, Oxford/Cambridge: Blackwell.

[10] General Secretary for Adult Education (n.d.). Study on the tackling of the educational problems of Roma, Athens, G.S.A.E.

[11] Gotovos A. (2006), Educational interventions for overcoming social marginalization: action and reaction, Education and Society, ed. 16, pp. 203-247.

[12] Gotovos A., (1996), Racism, Social, Psychological and Pedagogical aspects of an ideology and a practice, G.S.A.E., Athens

[13] Greek federation of Secondary Education State School Teachers' Centre for Study and Documentation (2000), School without borders. School exercises in Human Rights, Athens, C.S.D.

[14] Greek Group for Minority Rights (2002), Roma in Greece: History and Contemporary Reality, G.G.M.R Supplement.

[15] Greve B. (2002), Is a supranational strategy for social inclusion possible? Research Papers from the Department of Social Sciences. Roskilde University, Denmark.

[16] Hatzisavvidis S (2005), Linguistic minorities and school failure. The case of the Rom in the European Union, text retrieved 6/12/2005. Http://users.auth.gr/-sofronis/49ar.htm

[17] Karathanasi E. (2000), The Roma' dwelling. The bio-space and socio-space of the Roma. Social Science Library, publ. Gutenberg.

[18] Lenhart V. (2006), The pedagogy of Human Rights, Athens, Gutenberg. Contemporary Pedagogy.

[19] Liegeois J.P. \& Gheorghe N. (1995), Roma/Roma: A European Minority, Supplement of the Greek Minority Rights Group (June 002): The Roma in Greece: History and Contemporary Reality, MRG.

[20] Liegeois J.P. (1999), Roma, Roma, Travellers. The Roma of Europe, Athens, Kastaniotis, Laografia.

[21] Markou G. (2008), The attempt to develop a national policy for the economic and social integration of the Roma, in Troubeta S. (ed.). The Roma in the modern greek state. Coexistences, reversals, absences, Athens, publ. Kritiki.

[22] National Commission for Human Rights (2001), The situation of the Roma in Greece. Text retrieved 25/11/2005. Http://www.nchr.gr/category.php?category_id=61

[23] National Commission for Human Rights (2004), Observations of the National Commission for Human Rights on the draft of the first report of the Greek Democracy for the international pact for personal and political rights.

[24] Papadimitriou Z. (2000), Phenomena of social exclusion, xenophobia and racism in Greece, in Nestoras I., Pesmazoglou V., Samatas M (ed.) Contemporary Trends in Social Sciences, Sociology, Economy, Psychology, Athens, Typothito G. Dardanos.

[25] Pavli M. \& Sideri A. (1990), The Roma of St. Barbara's and Kato Achaia. Research Study, Athens, Ministry of Culture, G.S.A.E.

[26] Pizanias P., (1993), The cities' poor. Survival know-how in post-war Greece, Athens, publ. Themelio.

[27] Room G. \& Britton N. (2006), The dynamics of social exclusion. International Journal of Social Welfare. Blackwell Publishing, issue 15.

[28] Room G. (1999), Social Exclusion, solidarity and the challenge of globalization. International Journal of Social Welfare. Blackwell Publishing, issue 8.

[29] Silver H. (2006), European national policies to promote the social inclusion of disadvantaged groups. Retrieved: www.brownedu/Departments/Sociology/Faculty/hsilver/document/Ch.9-HSilver-REVIO-24pdf6/10/2006

[30] Silver H., Miller S. M. (2003), Social Exclusion. The European Approach to Social Disadvantage. Indicators, vol. 2 , issue 2.

[31] Terzopoulou M. \& Georgiou G. (1996), The Roma in Greece. History-Civilization, Athens, G.S.A.E.

[32] Vallerstain I. (1991a), The construction of peoples: racism, nationalism, patriotism, in Balibar E., Vallerstein I., Race, Nation, Class, differentiated identities, Athens, publ. O Politis.

[33] Vallerstain I. (1991b), The structures of households and the formation of the work force in the capitalist world economy, in Balibar E., Vallerstain I., Race, Nation, Class, differentiated identities, Athens, publ. O Politis.

[34] Vasileiadou M., Pavli-Korre M. (1996) The Education of Roma in Greece, Athens, G.S.A.E.

69 | P a g e

J u ly 2013 
[35] Vaxevanoglou A. (2001), Greek Roma. Marginalized and breadwinners, Athens, publ. Alexandreia.

[36] Vergidis D. (1995), Neo-racism and school. The case of Roma children, Contemporary Education, ed. 81, 1995, pp. 51-62.

[37] Vergidis D. (1996), The extracurricular literacy of Roma children in Kato Achaia. Research-action as a method of evaluation, in the proceedings of The International Symposium on the education of Roma. Development of web material, Athens, 6-9 April, 1995. Greek Ministry of Education, G.S.A.E. UNESCO, pp. 130-159.

[38] Vergidis D. (1998) Do Roma go to school? School integration of Roma children in Kato Achaia, ARETHAS Scientific Yearbook, University of Patras, School of Humanistic and Social Sciences, Department of Primary Education, Patra, pp. 41-69. 